\title{
Regeneração de plantas de laranja 'Pêra' via organogênese in vitro
}

\author{
Rosely Pereira da Silva ${ }^{(1)}$, Maria Angélica Pereira de Carvalho Costa $^{(1)}$, Antonio da Silva Souza ${ }^{(2)}$ \\ e Weliton Antonio Bastos de Almeida ${ }^{(1)}$
}

\begin{abstract}
(1)Universidade Federal da Bahia, Escola de Agronomia, CEP 44380-000 Cruz das Almas, BA. E-mail: rosely.silva@bol.com.br, mapcosta@ufba.com.br, weliton@ufba.br (2)Embrapa Mandioca e Fruticultura Tropical, CEP 44380-000 Cruz das Almas, BA. E-mail: assouza@cnpmf.embrapa.br
\end{abstract}

Resumo - O objetivo deste trabalho foi estabelecer um protocolo eficiente de regeneração de plantas in vitro, via organogênese em explante juvenil de laranja 'Pêra' (Citrus sinensis L. Osbeck), para atender futuros trabalhos de transformação genética. Segmentos de epicótilo utilizados como explantes foram introduzidos em meio de cultura MT. A fim de maximizar a regeneração de plantas in vitro, foram realizados experimentos para avaliar as concentrações de BAP no meio de cultivo $\left(0,1,2,3\right.$ ou $\left.4 \mathrm{mg} \mathrm{L}^{-1}\right)$, tamanho $(0,25,0,5$ ou $1 \mathrm{~cm})$, polaridade (basal, medial e apical), posição (horizontal ou vertical), condições de luminosidade (fotoperíodo de 16 horas e escuro por 30 dias) e seccionamento nas extremidades dos explantes, bem como melhores condições para garantir plantas enraizadas (meio MT, MT/2, com ou sem auxina e microenxertia). A combinação de $3 \mathrm{mg} \mathrm{L}^{-1}$ de BAP com segmentos de $0,25 \mathrm{~cm}$ de comprimento foi eficiente na resposta organogenética. Segmentos apicais e mediais apresentaram melhores resultados do que os basais. O cultivo dos segmentos na posição horizontal, em fotoperíodo de 16 horas, foi mais eficiente do que na posição vertical. Não houve melhora na indução da organogênese in vitro, quando foram seccionadas as extremidades dos explantes. A microenxertia assegurou $100 \%$ de brotos enraizados.

Termos para indexação: Citrus sinensis, cultura de tecidos, explante juvenil, benzilaminopurina, microenxertia.

\section{Regeneration of 'Pera' sweet orange plants through in vitro organogenesis}

\begin{abstract}
The objective of this work was to establish an efficient protocol for in vitro regeneration of plants through organogenesis of sweet orange 'Pera' (Citrus sinensis L. Osbeck) juvenile explants, in order to give support for future studies of genetic transformation. Epicotyl segments used as explants were introduced in MT culture media. To maximize the regeneration of in vitro plants, experiments were performed to evaluate different concentrations of BAP in the culture media $\left(0,1,2,3\right.$ or $\left.4 \mathrm{mg} \mathrm{L}^{-1}\right)$, size $(0.25,0.5$ or $1 \mathrm{~cm})$, polarity (basal, medium, and apical), position (horizontal or vertical), luminosity conditions (photoperiod of 16 hours, and darkness for 30 days), and incision of the segment ends. In addition, better conditions for obtaining rooted plants (culture media MT, MT/2, with and without auxin and micrografting) were studied. The combination of $3 \mathrm{mg} \mathrm{L}^{-1} \mathrm{BAP}$ with segments of $0.25 \mathrm{~cm}$ length was efficient for the organogenetic response. Segment apices and mediums were more efficient comparing to the basal parts. Culturing the segments in the horizontal position, with a photoperiod of 16 hours, was more efficient than in the vertical position. There was no improvement in the induction of in vitro organogenesis, when the explant ends were incised. Micrografting assured $100 \%$ of rooted shoots.
\end{abstract}

Index terms: Citrus sinensis, plant tissue culture, juvenile explants, benzilaminopurine, micrografting.

\section{Introdução}

A citricultura tem se destacado pela promoção do desenvolvimento socioeconômico brasileiro, pela contribuição com a balança comercial nacional e, principalmente, pela geração direta e indireta de empregos. Segundo a Abecitrus (2004), os empregos diretos gerados pelo setor citrícola somam 400 mil. O Brasil mantém a posição de maior produtor, bem como de maior exportador mundial de suco concentrado e congelado de laranja. Em 2003, o setor movimentou US\$ 3,23 bilhões, sendo US $\$ 1,33$ bilhão referente às exportações. O suco de laranja ocupou, nesse mesmo ano, a segunda posição entre os produtos comercializados no mercado internacional, logo abaixo das exportações de aviões.

Segundo Fernandes \& Bassanezi (2003), as variedades de laranja doce (Citrus sinensis L. Osbeck) mais utilizadas para fins industriais são 'Pêra', 'Valência', 
'Natal' e 'Hamlin', que representam 85\% das laranjeiras cultivadas, com 193,2 milhões de plantas. A variedade 'Pêra', com 82 milhões de árvores, representa 36\%. A laranja 'Pêra' é predominante e chega a ser quase exclusiva nos Estados da Bahia, Sergipe, Paraná e Minas Gerais.

Embora as condições edafoclimáticas favoreçam a cultura dos citros em várias regiões do Brasil, nossa produtividade média ainda é extremamente baixa, quando comparada com a de outros países (Machado, 1997), e cresce a cada dia o número de produtores em busca do aumento da produção por meio de ganhos de produtividade com a adoção de melhores tecnologias (Marino \& Mendes, 2003).

No Brasil, o melhoramento genético dos citros foi sempre muito mais uma atividade de coleta, manutenção e seleção massal de variantes espontâneos (Machado, 1997). As barreiras impostas pela biologia reprodutiva dos citros têm dificultado seu melhoramento pelo método convencional (Ollitraut \& Luro, 1995). A incorporação de técnicas biotecnológicas no melhoramento dessas espécies permite facilitar e acelerar a utilização da variedade disponível (Grosser \& Gmitter Junior, 1990), bem como utilizar germoplasma ainda não explorado (Grosser et al., 1996). Essas técnicas devem ser consideradas complementares às envolvidas nos programas tradicionais de melhoramento, tendo-se em vista um aumento da eficiência (redução tempo/recurso) na obtenção de variedades melhoradas (Amaral et al., 2001).

A transformação genética está se tornando uma importante ferramenta, dentro dos programas de melhoramento genético de citros, e uma alternativa para contornar barreiras naturais da espécie (Almeida et al., 2003). Entretanto, o sucesso na produção de plantas transgênicas depende de alguns requisitos, como a existência de uma metodologia eficiente de regeneração de plantas in vitro, bem como de um sistema de transformação genética que permita a introdução eficiente de genes (Pérez-Molphe-Balch \& Ochoa-Alejo, 1997).

Diversos trabalhos têm sido desenvolvidos para o estabelecimento de protocolos eficientes de regeneração de plantas in vitro via organogênese, com vistas à sua utilização na transferência gênica. Vários fatores podem influenciar no potencial regenerativo de uma espécie, como o genótipo utilizado, os tipos e dosagens de reguladores vegetais, os tipos e tamanhos de explantes, os meios de cultura utilizados e as condições de cultivo (Bered et al., 1998). Dentre esses, destacam-se os reguladores vegetais como os principais controladores da morfogênese in vitro. O BAP tem sido a citocinina mais utilizada para promover a multiplicação em diversas espécies, e parece ser a mais adequada para a multiplicação da parte aérea e indução de gemas adventícias (Grattapaglia \& Machado, 1998).

O objetivo deste trabalho foi estabelecer um protocolo eficiente de regeneração de plantas in vitro, via organogênese em explante juvenil de laranja 'Pêra', que possa ser compatível com processos de transferência gênica por métodos biobalísticos ou por Agrobacterium.

\section{Material e Métodos}

O trabalho foi conduzido no Laboratório de Cultura de Tecidos de Plantas, do Dep. de Fitotecnia da Escola de Agronomia da Universidade Federal da Bahia.

Sementes de frutos maduros de laranja 'Pêra' (Citrus sinensis L. Osbeck) tiveram seus tegumentos retirados e foram desinfestadas em solução comercial de hipoclorito de sódio e água (1:1), durante 20 minutos. Em seguida, foram lavadas três vezes em água estéril e incubadas em tubos de ensaio com $15 \mathrm{~mL}$ de meio de cultura MT (Murashige \& Tucker, 1969), acrescido de $25 \mathrm{~g} \mathrm{~L}^{-1}$ de sacarose, solidificado com ágar $(0,8 \%)$ e mantido a $27 \pm 2^{\circ} \mathrm{C}$ em ausência de luz, por três semanas, seguidas de duas semanas sob fotoperíodo de 16 horas ( $40 \mu \mathrm{mol} \mathrm{m}{ }^{-2} \mathrm{~s}^{-1}$ de intensidade luminosa). Após esse período, segmentos de epicótilo das plântulas germinadas foram utilizados como explantes, para as avaliações de indução de organogênese in vitro.

Para induzir à formação de gemas adventícias, os explantes foram cultivados em placa de Petri com $20 \mathrm{~mL}$ de meio de cultura MT, acrescido de $25 \mathrm{~g} \mathrm{~L}^{-1}$ de sacarose, solidificado com ágar (0,8\%), suplementado com concentrações de BAP; em seguida, os explantes foram incubados em câmara de crescimento a $27 \pm 2^{\circ} \mathrm{C}$.

Para maximizar a regeneração de plantas in vitro, foram verificados o efeito de diferentes comprimentos de segmentos de epicótilo e da polaridade, na resposta organogenética dos segmentos in vitro.

Os segmentos de epicótilo foram seccionados em 0,25 , 0,50 e $1 \mathrm{~cm}$ de comprimento, introduzidos em meio de cultura MT suplementado com BAP $\left(0,1,2\right.$ ou $\left.3 \mathrm{mg} \mathrm{L}^{-1}\right)$, e foram incubados em condições de fotoperíodo de 16 horas.

Para análise do efeito da polaridade, os epicótilos de plantas germinadas in vitro (aproximadamente $9 \mathrm{~cm}$ de comprimento) foram divididos em três partes (basal, 
medial e apical), seccionados em aproximadamente $1 \mathrm{~cm}$ de comprimento, cultivados separadamente em meio MT suplementado com BAP $\left(0,1,2\right.$ ou $\left.3 \mathrm{mg} \mathrm{L}^{-1}\right)$ e incubados em condições de fotoperíodo de 16 horas.

Foram ainda verificados o efeito da posição de cultivo dos explantes na organogênese in vitro, em diferentes condições de luminosidade, e o efeito do seccionamento nas extremidades dos explantes, em condições variadas de cultivo.

Segmentos de epicótilo, com aproximadamente $1 \mathrm{~cm}$ de comprimento, foram introduzidos no meio de cultura MT suplementado com BAP $\left(0,1,2,3\right.$, ou $\left.4 \mathrm{mg} \mathrm{L}^{-1}\right)$, em posições horizontal e vertical, em condições de escuro por 30 dias, e diretamente sob fotoperíodo de 16 horas.

Para verificação do efeito do seccionamento nas extremidades dos explantes, segmentos de epicótilo com aproximadamente $1 \mathrm{~cm}$ de comprimento foram seccionados nas extremidades (2-3 mm), introduzidos no meio de cultura MT suplementado com BAP $(0,1$ ou $2 \mathrm{mg} \mathrm{L}^{-1}$ ) e cultivados em condições de escuro por 30 dias, bem como diretamente em fotoperíodo de 16 horas.

Em todos os experimentos realizados, o delineamento experimental foi o inteiramente casualizado em esquema fatorial, com cinco repetições, cada qual constituída por uma placa com vinte segmentos. Após 45 dias de cultivo, foram avaliados o porcentual de explantes responsivos e o número de gemas por explante responsivo.

As brotações obtidas - gemas desenvolvidas com cerca de $1 \mathrm{~cm}$ de comprimento - foram transferidas para meio $\mathrm{MT}+1 \mathrm{mg} \mathrm{L}^{-1}$ de ácido giberélico $\left(\mathrm{GA}_{3}\right)$, para promoção do alongamento, onde permaneceram por 60 dias, para então serem submetidas à indução de enraizamento. Para induzir à formação de raízes e assegurar o enraizamento das brotações regeneradas in vitro, foram analisados o efeito de concentrações de sais do meio MT combinadas com diferentes auxinas e a microenxertia dos brotos regenerados.

Brotações regeneradas in vitro, oriundas das concentrações 0 , 1 e $2 \mathrm{mg} \mathrm{L}^{-1}$ de BAP, foram transferidas para os seguintes meios de cultura: MT + 0,5 g L ${ }^{-1}$ de carvão ativado; $\mathrm{MT}+0,5 \mathrm{~g} \mathrm{~L}^{-1}$ de carvão ativado $+1 \mathrm{mg} \mathrm{L}^{-1}$ de ANA; MT + 0,5 g L ${ }^{-1}$ de carvão ativado + $1 \mathrm{mg} \mathrm{L}^{-1}$ de IBA; metade dos sais de $\mathrm{MT}+0,5 \mathrm{~g} \mathrm{~L}^{-1}$ de carvão ativado; metade dos sais de $\mathrm{MT}+0,5 \mathrm{~g} \mathrm{~L}^{-1}$ de carvão ativado $+1 \mathrm{mg} \mathrm{L}^{-1}$ de ANA; metade dos sais de MT + $0,5 \mathrm{~g} \mathrm{~L}^{-1}$ de carvão ativado $+1 \mathrm{mg} \mathrm{L}^{-1}$ de IBA. As brotações foram cultivadas em câmara de crescimento, a $27 \pm 2^{\circ} \mathrm{C}$, sob fotoperíodo de 16 horas, durante
60 dias. O delineamento experimental foi o inteiramente casualizado, em esquema fatorial $6 \times 3$ (seis meios de cultura e três concentrações inicias de BAP), com cinco repetições, cada uma constituída por um frasco com quatro brotos. Foi avaliado o porcentual de brotos que emitiram raízes.

Como alternativa para garantir plantas com raízes e maximizar a regeneração, foi feita a microenxertia dos ápices caulinares das brotações obtidas em 50 plântulas de limão 'Cravo' e 50 de tangerina 'Cleópatra' germinadas in vitro. A microenxertia consistiu na introdução, em condições assépticas, de um ápice caulinar com duas a três folhas, excisado de uma brotação regenerada in vitro, sobre um porta-enxerto decapitado a $5 \mathrm{~cm}$ dos cotilédones. Na extremidade decapitada foi realizado um corte em $\mathrm{T}$ invertido, para inserção do ápice meristemático sob a casca, para assegurar o contato com o sistema vascular do porta-enxerto. Após 30 dias, foi avaliado o porcentual de pegamento e, posteriormente, as plantas foram aclimatizadas.

A aclimatização foi realizada em copos de plástico descartáveis contendo terra vegetal autoclavada, e cobertos com sacos de plástico para manter a umidade. Esses sacos foram mantidos por 30 dias com irrigação diária, tendo-se deixado a planta sem a cobertura plástica por uma hora e aumentado, gradativamente, esse tempo até a sua remoção total.

As variáveis avaliadas foram submetidas à análise de variância. Para as variáveis que apresentaram diferenças significativas para concentrações acima de três doses, foram feitas análises de regressão. A comparação dos demais resultados foi feita pelo teste de Tukey a $5 \%$ de probabilidade. Foi utilizado o programa estatístico Sisvar - Sistema de análises de variância para dados balanceados.

\section{Resultados e Discussão}

Não houve interação significativa entre as concentrações de BAP avaliadas e o comprimento de segmentos de epicótilo, para nenhuma das variáveis estudadas. Entretanto, o efeito isolado das concentrações de BAP sobre o porcentual de explante responsivo (Figura 1) demonstrou que, na concentração $3 \mathrm{mg} \mathrm{L}^{-1}$ de BAP, foi obtido o maior porcentual de explante responsivo. Com relação ao efeito isolado do tamanho dos segmentos (Tabela 1), destacaram-se aqueles de 0,5 e $1 \mathrm{~cm}$, com $97,4 \%$ e $97 \%$, respectivamente, de explantes 
responsivos, que diferiram, estatisticamente, dos segmentos de $0,25 \mathrm{~cm}(85,5 \%)$. Ao se analisar o número de gemas por explante responsivo, verificou-se que a concentração de $3 \mathrm{mg} \mathrm{L}^{-1}$ proporcionou a melhor resposta (Figura 1), porém no efeito isolado do tamanho dos segmentos se destacaram os de $0,25 \mathrm{~cm}$ (Tabela 1), que diferiram significativamente dos demais. $\mathrm{Na}$ análise geral desses resultados pode-se considerar que a concentração de $3 \mathrm{mg} \mathrm{L}^{-1}$ de BAP, combinada com segmentos de aproximadamente $0,25 \mathrm{~cm}$ de comprimento, garantiu a formação de maior número de gemas adven-
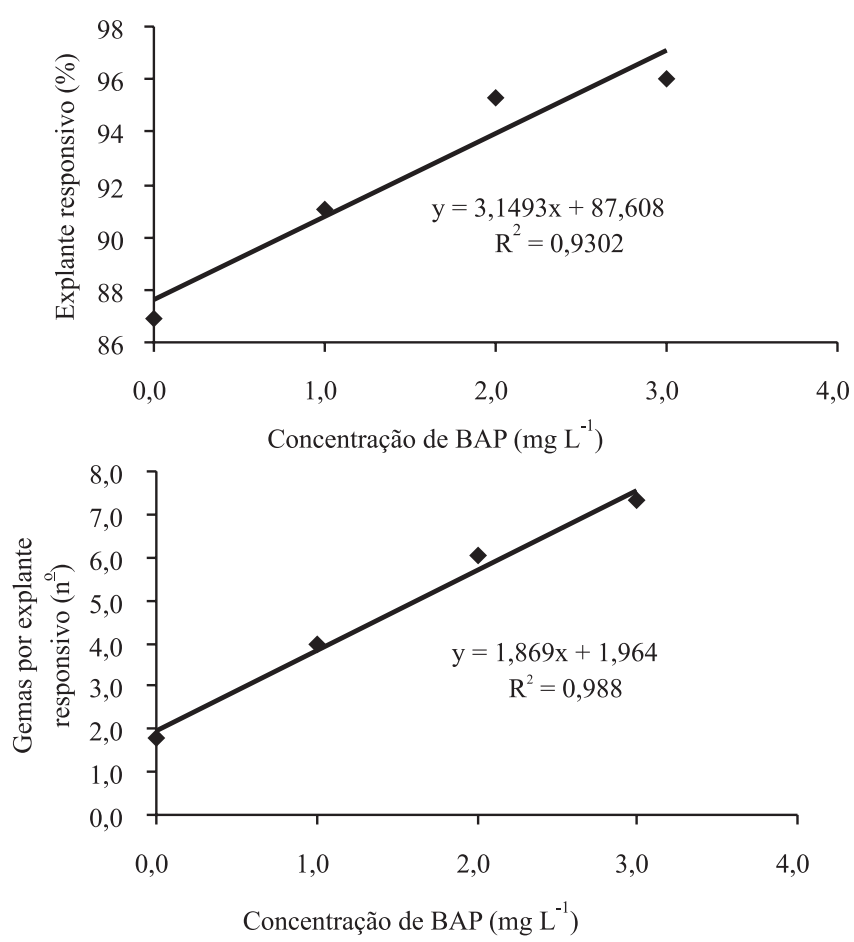

Figura 1. Porcentual de explantes responsivos de laranja 'Pêra' (Citrus sinensis L. Osbeck) e número de gemas por explante responsivo, em função de concentrações de BAP.

Tabela 1. Porcentual de explantes responsivos e número de gemas por explante de laranja 'Pera' (C. sinensis L. Osbeck), em função de diferentes comprimentos do segmento de epicótilo $^{(1)}$.

\begin{tabular}{ccc}
\hline $\begin{array}{c}\text { Comprimento do } \\
\text { explante }(\mathrm{cm})\end{array}$ & $\begin{array}{c}\text { Explantes } \\
\text { responsivos }(\%)\end{array}$ & $\begin{array}{c}\text { Gemas por explante } \\
\left(\mathrm{n}^{\mathrm{o}}\right)\end{array}$ \\
\hline 0,25 & $85,5 \mathrm{~b}$ & $6,11 \mathrm{a}$ \\
0,50 & $97,4 \mathrm{a}$ & $4,33 \mathrm{~b}$ \\
1,00 & $97,0 \mathrm{a}$ & $4,31 \mathrm{~b}$ \\
\hline
\end{tabular}

(1)Valores seguidos da mesma letra, em cada variável, não diferem entre si pelo teste de Tukey a $5 \%$ de probabilidade. tícias, pois, partindo-se inicialmente de 100 explantes, é possível obter-se aproximadamente 586 gemas (96\% de explantes responsivos x 6,1 gemas por explante responsivo). Tal resultado diverge do encontrado por Burger \& Hackett (1986), que ao estudarem diferentes tamanhos de segmentos de epicótilo de laranja 'Valência', obtiveram maior número de gemas por explante em segmentos com $2 \mathrm{~cm}$ de comprimento. Possivelmente, essa diferença deve estar relacionada ao potencial genético de cada variedade.

Houve efeito significativo da interação concentração $\mathrm{x}$ polaridade do segmento de epicótilo, em relação ao número de gemas por explante responsivo (Figura 2). Os segmentos apicais apresentaram efeito linear positivo, tendo mostrado que nas maiores concentrações de BAP foram obtidos os maiores números de gemas, com destaque para a concentração de $3 \mathrm{mg} \mathrm{L}^{-1}$ de BAP. Os segmentos mediais e basais mostraram melhores respostas também na concentração de $3 \mathrm{mg} \mathrm{L}^{-1}$ de BAP, porém, com comportamento diferente dos segmentos apicais. Essa concentração proporcionou número de gemas por explante superior a 7 nos segmentos apicais e mediais. Os segmentos basais, próximos aos cotilédones, foram os menos expressivos nesse trabalho. Burger \& Hackett (1986), ao estudarem o efeito da polaridade em segmentos de epicótilo de laranja 'Valência', encontraram a melhor resposta nos segmentos próximos aos cotilédones. Bordón et al. (2000), quando avaliaram o efeito da polaridade em segmentos de epicótilo de citrange 'Troyer' (Citrus sinensis L. Osbeck $\mathrm{x}$ Poncirus trifoliata Raf.), encontraram melhores respostas em segmentos próximos do ápice. Em função desses resultados, pode-se considerar que o efeito da polari-

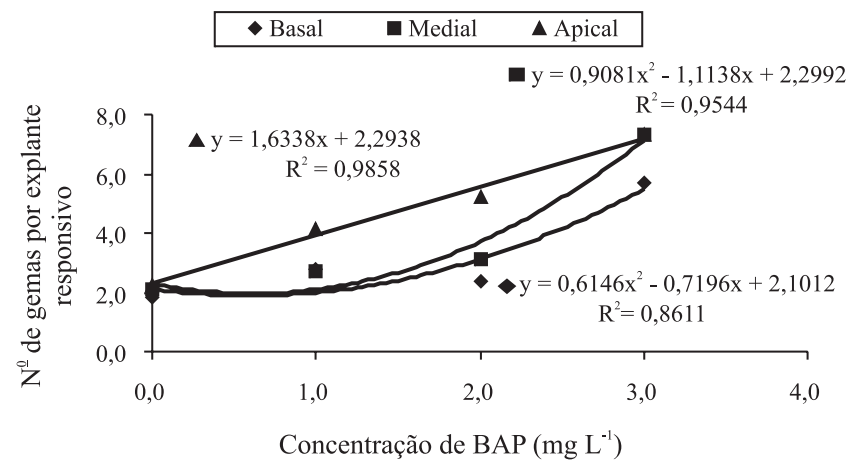

Figura 2. Número de gemas por explante responsivo de laranja 'Pêra' (C. sinensis L. Osbeck), em função da polaridade do segmento de epicótilo e de concentrações de BAP. 
dade em segmentos de epicótilo de citros é dependente do genótipo.

Nos explantes cultivados em condições de fotoperíodo de 16 horas, não se constatou diferença significativa entre as concentrações para a variável porcentual de explante responsivo. Entretanto, para o número de gemas por explante, verificou-se que houve efeito significativo da interação concentração x posição de cultivo (Figura 3).

Os explantes cultivados horizontalmente mostraramse mais eficientes para indução da organogênese adventícia in vitro. A regressão linear, conforme se observa na Figura 3, demonstrou que quanto maior a concentração de BAP no meio de cultura, maior o número de gemas por explante, tendo-se destacado, neste trabalho, a concentração $4 \mathrm{mg} \mathrm{L}^{-1}$ de BAP como a de maior resposta.

Em relação aos explantes cultivados verticalmente, a concentração ótima estimada para o cultivo dos explantes foi 2,6 $\mathrm{mg} \mathrm{L}^{-1}$, a partir da qual o número de gemas por explante é decrescente.

Para os explantes cultivados em condições de 30 dias no escuro, verificou-se que tanto para a variável porcentual de explante responsivo, como para o número de gemas por explante responsivo, não houve efeito significativo da interação BAP x posição do explante.

A Figura 4 ilustra o efeito isolado do BAP, observando-se que as concentrações $3 \mathrm{mg} \mathrm{L}^{-1}$ ou $4 \mathrm{mg} \mathrm{L}^{-1}$ mostraram-se mais expressivas na indução da organogênese, com aproximadamente 5,5 gemas por explante. Assim,

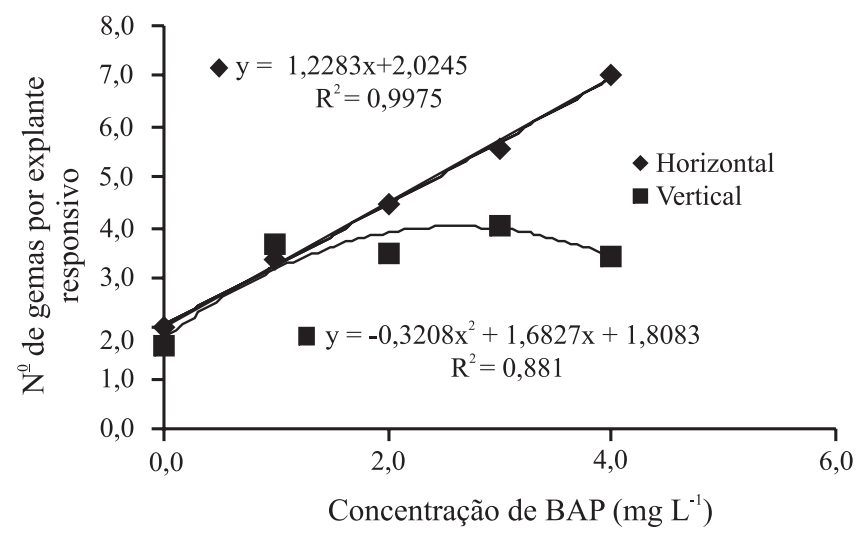

Figura 3. Número de gemas por explante responsivo de laranja 'Pêra' (C. sinensis L. Osbeck), em função da posição do segmento de epicótilo no meio de cultura e de concentrações de BAP, cultivados em condições de fotoperíodo de 16 horas. o cultivo dos explantes na posição horizontal, em condições de fotoperíodo de 16 horas, mostrou-se mais favorável à indução da organogênese in vitro, tendo proporcionado aproximadamente 7 gemas por explante responsivo, na concentração de $4 \mathrm{mg} \mathrm{L}^{-1}$ de BAP, superior aos demais tratamentos. Tais resultados estão de acordo com os obtidos por Moreira-Dias et al. (2000), que observaram melhores respostas para o número de gemas, em segmentos de epicótilo de citrange 'Troyer', quando cultivaram os explantes em condições de luminosidade (fotoperíodo de 16 horas) e na posição horizontal. Entretanto, Mendes et al. (2002), ao estudarem a transformação genética a partir de segmentos de epicótilo de laranja 'Hamlin', constataram que o cultivo dos segmentos juntamente com com Agrobacterium na ausência de luminosidade, foi mais eficiente na regeneração e obtenção de brotos GUS ${ }^{+}$.

Almeida et al. (2003) realizaram estudos anatômicos em segmentos internodais de citros, cultivados in vitro, e constataram que as gemas adventícias têm origem endógena, mais precisamente, formando-se por sucessivas divisões das células cambiais. Moura et al. (2001) induziram maior número de gemas por explante, quando seccionaram as extremidades dos explantes de citros e relataram que esse aumento está relacionado com uma maior formação de zonas meristemáticas, em função do corte nos tecidos.

Os trabalhos com transformação genética de citros têm demonstrado que a eficiência de transferência gênica, via Agrobacterium, tem sido baixa. Almeida et al. (2002, 2003) relatam que essa baixa eficiência pode estar relacionada com a dificuldade de contato da Agrobacterium com as células competentes à morfogênese in vitro.

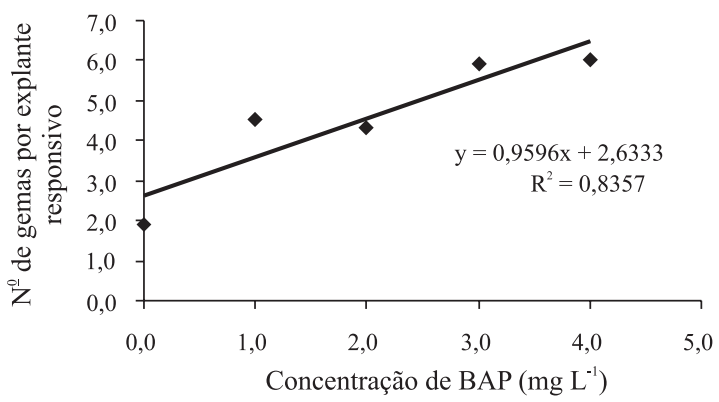

Figura 4. Número de gemas por explante responsivo de laranja 'Pêra' (C. sinensis L. Osbeck) cultivados em condições de escuro por 30 dias, em função de concentrações de BAP. 
A interação entre concentrações de BAP e condições de luminosidade não foi significativa. Quando cultivados em condições de fotoperíodo de 16 horas, os segmentos de epicótilo resultaram em maiores porcentuais de explantes responsivos $(83,2 \%)$, se comparados aos cultivados na ausência de luminosidade por 30 dias (53,9\%).

Para o número de gemas por explante responsivo, houve efeito significativo apenas da concentração isolada, onde se verificou que a concentração $2 \mathrm{mg} \mathrm{L}^{-1}$ de BAP promoveu maior resposta em explantes seccionados nas extremidades, que diferiu estatisticamente das demais (Tabela 2). O número máximo de gemas por explante responsivo aqui obtido $(2,57)$ foi inferior ao de outros experimentos realizados neste trabalho, onde não foi seccionada a extremidade dos explantes.

A maioria dos trabalhos de indução de enraizamento in vitro tem utilizado auxinas como reguladores vegetais ou ausência de reguladores. Outros trabalhos têm utilizado diluições de sais minerais nos meios de cultura em diversas frutíferas, tais como maçã (Pasqual et al., 2000), maracujá (Biasi et al., 2000), banana (Oliveira et al., 2001) e citros (Almeida et al., 2002), com resultados positivos no enraizamento.

Neste trabalho, os melhores resultados para o enraizamento das brotações ocorreram quando se utilizou o tratamento na ausência de auxina, para as brotações oriundas do tratamento com $1 \mathrm{mg} \mathrm{L}^{-1}$ de BAP, na fase de indução da organogênese; ou quando se empregou o meio MT/2 + $1 \mathrm{mg} \mathrm{L}^{-1}$ de IBA, para as brotações oriundas do tratamento com $0 \mathrm{mg} \mathrm{L}^{-1}$ de BAP, na fase de indução da organogênese, com porcentual de enraizamento de aproximadamente $58 \%$ e $56 \%$, respectivamente (Figura 5). Esses porcentuais são considerados baixos, quando comparados com outros trabalhos de citros, nos quais foram obtidos índices de 80\% em laranja doce 'Pineapple' (Duran-Vila et al., 1992), 84\% em Citrus macrophylla (Ghorbel et al.,

Tabela 2. Número de gemas por explante responsivo de laranja 'Pera' (C. sinensis L. Osbeck), em função do seccionamento das extremidades dos explantes e de concentrações de BAP, independente das condições de luminosidade ${ }^{(1)}$.

\begin{tabular}{cc}
\hline $\begin{array}{c}\text { Concentração de BAP } \\
\left(\mathrm{mg} \mathrm{L}^{-1}\right)\end{array}$ & $\begin{array}{c}\text { Gemas por explante responsivo } \\
\left(\mathrm{n}^{\mathrm{o}}\right)\end{array}$ \\
\hline 0,0 & $1,45 \mathrm{~b}$ \\
1,0 & $1,58 \mathrm{~b}$ \\
2,0 & $2,57 \mathrm{a}$ \\
\hline
\end{tabular}

(1)Valores seguidos da mesma letra não diferem entre si pelo teste de Tukey a $5 \%$ de probabilidade.

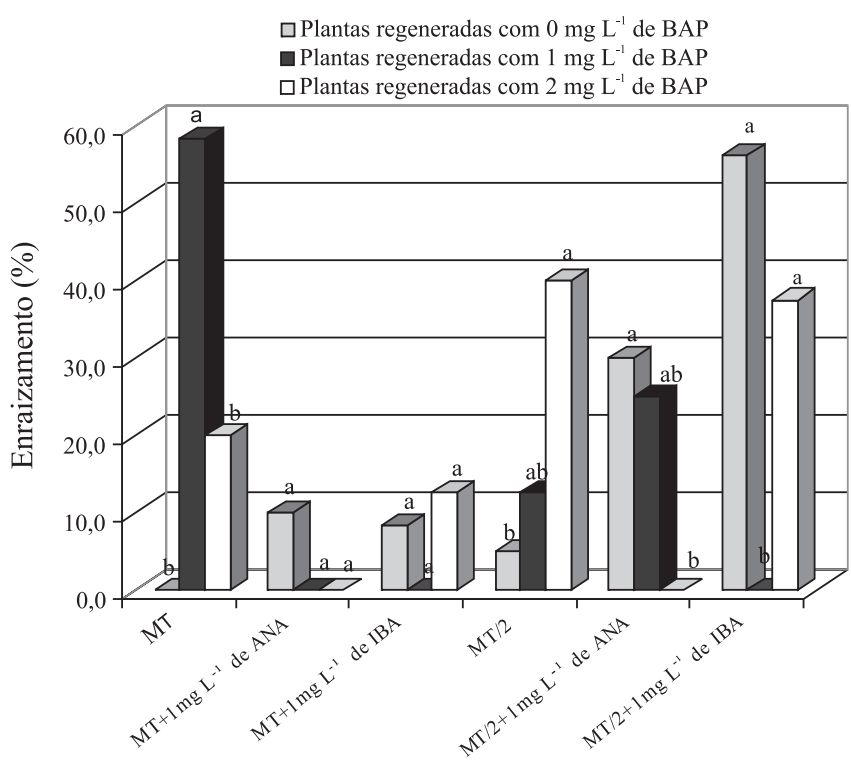

Figura 5. Porcentual de enraizamento de brotos de laranja Pêra (C. sinensis L. Osbeck), em função de concentrações de BAP e diferentes concentrações de sais no meio de cultura. Colunas com a mesma letra, em cada meio de cultura, não diferem entre si pelo teste de Tukey a 5\% de probabilidade.

1998) e 70\% em tangerina 'Mônica' (Pérez-MolpheBalch \& Ochoa-Alejo, 1997).

Trabalhos de transformação genética de citros (Peña et al., 1995, 1997; Cervera et al., 2000; Almeida et al., 2002, 2003) têm realizado microenxertia de brotações regeneradas in vitro, em virtude do baixo índice de enraizamento. Neste trabalho, foi obtido $100 \%$ de pegamento das brotações microenxertadas.

\section{Conclusões}

1. A combinação da concentração $3 \mathrm{mg} \mathrm{L}^{-1}$ de BAP, com segmentos de epicótilo de $0,25 \mathrm{~cm}$ de comprimento, proporciona a melhor resposta na indução de gemas adventícias in vitro.

2. Os segmentos de epicótilo mediais e apicais mostram-se mais eficazes na resposta organogenética in vitro, quando comparados com os segmentos basais.

3. O cultivo de segmentos de epicótilo na posição horizontal, em condições de fotoperíodo de 16 horas, é mais eficiente na resposta organogenética que aqueles cultivados verticalmente.

4. O máximo enraizamento das brotações é obtido quando se utiliza o meio MT na ausência de auxina, ou MT/2 adicionado de $1 \mathrm{mg} \mathrm{L}^{-1}$ de IBA.

5. A microenxertia proporciona $100 \%$ de brotos enraizados. 


\section{Referências}

ABECITRUS. Novo mapeamento do sistema agroindustrial citrícola: informativo [de] 30 [de] setembro [de] 2004. Disponível em: <http://www.abecitrus.com.br/informa.html>. Acesso em: 18 nov. 2004.

ALMEIDA, W.A.B. de; MOURÃO FILHO, F. de A.A.; MENDES, B.M.J.; RODRIGUEZ, A.P.M. In vitro organogenesis optimization and plantlet regeneration in Citrus sinensis and C. limonia. Scientia Agricola, v.59, p.35-40, 2002.

ALMEIDA, W.A.B. de; MOURÃO FILHO, F. de A.A.; PINO, L.E.; RODRIGUEZ, A.P.M.; MENDES, B.M.J. Genetic transformation and plant recovery from mature tissues of Citrus sinensis L. Osbeck. Plant Science, v.164, p.203-211, 2003.

AMARAL, A.M. de; MACHADO, M.A.; PAIVA, L.V. Uso da biotecnologia na citricultura. Informe Agropecuário, v.22, p.95100, 2001.

BERED, F.; SERENO, M.J.C.M.; CARVALHO, F.I.F. de; LANGE, C.E.; HANDEL, C.L.; DORNELLES, A.L.C. Regeneração de plantas de aveia a partir de calos embriogênicos e organogênicos. Pesquisa Agropecuária Brasileira, v.33, p.1827-1833, 1998.

BIASI, L.A.; FALCO, M.C.; RODRIGUEZ, A.P.M.; MENDES, B.M.J. Organogênese a partir de segmento internodal de maracujá amarelo. Scientia Agricola, v.57, p.661-665, 2000.

BORDÓN, Y.; GUARDIOLA, J.L.; GARCIA-LUIS, A. Genotype affects the morphogenic response in vitro of epicotyl segments of citrus rootstocks. Annals of Botany, v.85, p.159-166, 2000.

BURGER, D.W.; HACKETT, W.P. Gradient of adventitious bud formation on excised epicotyl and root sections of citrus. Plant Science, v.43, p.229-232, 1986.

CERVERA, M.; ORTEGA, C.; NAVARRO, A.; NAVARRO, L.; PEÑA, L. Generation of transgenic citrus plants with the toleranceto-salinity gene HAL2 from yeast. Journal of Horticultural Science and Biotechnology, v.75, p.26-30, 2000.

DURÁN-VILA, N.; GORGOCENA, Y.; ORTEGA, V.; ORTIZ, J.; NAVARRO, L. Morphogenesis and tissue culture of sweet orange (Citrus sinensis (L.) Osb.): effect of temperature and photosynthetic radiation. Plant Cell, Tissue and Organ Culture, v.29, p.11-18, 1992.

FERNANDES, N.G.; BASSANEZI, R.B. Morte súbita dos citros. Fitopatologia Brasileira, v.28, p.66-72, 2003.

GHORBEL, B.R.; NAVARRO, L.; DURÁN-VILA, N. Morphogenesis and regeneration of whole plants of grapefruit (Citrus paradisi), sour orange (C. aurantium) and alemow (C. macrophylla). Journal of Horticultural Science and Biotechnology, v.73, p.323327, 1998.

GRATTAPAGLIA, D.; MACHADO, M.A. Micropropagação. In: TORRES, A.C.; CALDAS, L.S.; BUSO, J.A. Cultura de tecidos e transformação genética de plantas. Brasília: Embrapa-SPI, 1998. v.1, p.183-260.
GROSSER, J.W.; GMITTER JUNIOR, F. Protoplast fusion and citrus improvement. Plant Breeding Reviews, v.8, p.339-374, 1990. GROSSER, J.W.; MOURÃO FILHO, F.A.A.; GMITTER JUNIOR, F.; LOUZADA, E.S.; JIANG, J.; BAERGEN, K.; QUIROS, A.; CABASSON, C.; SCHELL, J.L.; CHADLER, J.L. Allotetraploid hybrids between Citrus and seven related genera produced by somatic hybridization. Theoretical and Applied Genetics, v.92, p.577582, 1996.

MACHADO, M.A. Biotecnologia na citricultura. Biotecnologia, Ciência \& Desenvolvimento, v.1, p.8-10, 1997.

MARINO, L.K.; MENDES, M. Mercado e perspectivas para a citricultura. Citricultura Atual, v.37, p.10-11, 2003.

MENDES, B.M.J.; BOSCARIOL, R.L.; MOURÃO FILHO, F. de A.A.; ALMEIDA, W.A.B. de. Agrobacterium-mediated genetic transformation of 'Hamlin' sweet orange. Pesquisa Agropecuária Brasileira, v.37, p.955-961, 2002.

MOREIRA-DIAS, J.M.; MOLINA, R.V.; BORDÓN, Y.; GUARDIOLA, J.L.; GARCIA-LUIS, A. Direct and indirect shoot organogenic pathways in epicotyl cuttings of troyer citrange differ in hormone requirements and their response to light. Annals of Botany, v.85, p.103-110, 2000.

MOURA, T.L. de M.; ALMEIDA, W.A.B. de; MENDES, B.M.J.; MOURÃO FILHO, F.A.A. Organogênese in vitro de Citrus em função de concentrações de BAP e seccionamento do explante. Revista Brasileira de Fruticultura, v.23, p.240-245, 2001.

MURASHIGE, T.; TUCKER, D.R.H. Growth factor requirement of citrus tissue culture. In: INTERNATIONAL CITRUS SYMPOSIUM, 1., 1969, Riverside. Proceedings. Riverside: University of California, 1969. p.1155-1169.

OLIVEIRA, R.P. de; SILVEIRA, D.G; SILVA, S. de O. Concentração de BAP e a eficiência de micropropagação de bananeira tetraplóide (Grupo AAAB). Scientia Agricola, v.58, p.73-78, 2001.

OLLITRAUT, P.; LURO, F. Amélioration des agrumes et biotechnologie. Fruits, v.50, p.267-279, 1995.

PASQUAL, M.; SILVA, A.B. da; MACIEL, A.L.R.; PEREIRA, A.B.; CAVALCANTE-ALVES, J.M. Enraizamento in vitro de portaenxerto de macieira em diversos substratos. Scientia Agricola, v.57, p.781-784, 2000.

PEÑA, L.; CERVERA, M.; JUAREZ, J.; NAVARRO, A.; PINA, J.A.; NAVARRO, L. Genetic transformation of lime (Citrus aurantifolia): factors affecting transformation and regeneration. Plant Cell Reports, v.15, p.731-737, 1997.

PEÑA, L.; CERVERA, M.; JUAREZ, J.; ORTEGA, C.; PINA, J.A.; DURÁN-VILA, N.; NAVARRO, L. High efficiency Agrobacterium-mediated transformation and regeneration of Citrus. Plant Science, v.104, p.183-191, 1995.

PÉREZ-MOLPHE-BALCH, E.; OCHOA-ALEJO, N. In vitro plant regeneration of Mexican lime and mandarin by direct organogenesis. HortScience, v.32, p.931-934, 1997.

Recebido em 18 de janeiro de 2005 e aprovado em 3 de maio de 2005 